\title{
The susceptibility of Proteus mirabilis and Enterococcus faecalis to various antimicrobial agents in polymicrobial biofilms formed using a drip flow reactor
}

\author{
Didem KART (ic) \\ Department of Pharmaceutical Microbiology, Faculty of Pharmacy, Hacettepe University, Ankara, Turkey \\ Corresponding Author: Didem KART_E-mail: dturk@hacettepe.edu.tr \\ Submitted: $30.06 .2019 \quad$ Accepted: 15.08 .2019
}

\begin{abstract}
Objectives: Interspecies interactions in poly-species biofilm are substantial. Our aim is to set up dynamic biofilm models of Enterococcus faecalis and Proteus mirabilis using Drip Flow Biofilm Reactor (DFR) and to evaluate the effect of these dual population on anti-biofilms of some antimicrobials.

Materials and Methods: E.faecalis and P.mirabilis biofilms were formed in a DFR. Influences of the dual interactions on their susceptibilities to antimicrobial agents (disinfectants, antibiotics and probiotic strains) were determined.

Results: Gluteraldehyde and quaternary ammonium compounds (QAC) effectively killed the cells in both biofilms of E.faecalis and P.mirabilis. However, the efficacy of hydrogen peroxide $\left(\mathrm{H}_{2} \mathrm{O}_{2}\right)$ was dependant on the microbial species present. P. mirabilis was less susceptible to the ampicillin and ciprofloxacin in co-culture compared to when cultured alone. Here, the influence of the presence of E.faecalis on P.mirabilis susceptibility was determined. For high concentrations of ciprofloxacin (1024 and $512 \mu \mathrm{g} / \mathrm{ml})$, the $\log$ reduction in P.mirabilis cells was determined as approximately 4.5 and 3.5 in mono and dual-species biofilms respectively. Compared to B.lactis, L.acidophilus was found to be more effective both on single and dual species.

Conclusion: The effect of antimicrobial agents on microbial cells in a polymicrobial biofilm may depend on the composition of the biofilm.

Keywords: Polymicrobial biofilm, E. faecalis, P. mirabilis, Antimicrobial, Drip flow reactor, Probiotic strains
\end{abstract}

\section{INTRODUCTION}

Cells in biofilms are embedded in a self-produced extracellular polymeric matrix (EPM) that mainly consist polysaccharides, DNA, proteins, and dead cells [1]. In biofilms, the limited penetration of antimicrobial agents and accumulation of antibiotic-degrading enzymes are observed due to EPM production. EPM formation and the transfer of resistance genes in the presence of high cell density lead to an increased biofilm resistance [1,2].

Multi-species biofilms that exist in the human body are complex communities in which cells of various microorganisms are present and live together [1]. These biofilms are commonly encountered clinical concern and are found in multiple body sites (such as the skin, teeth and mucosa) in chronically infected wounds and on indwelling medical devices such as prostheses, stents, implants, catheters and endotracheal tubes [3].

P. mirabilis is associated with a large number of human infections such as catheter-associated urinary tract infection (CAUTI), cystitis, pyelonephritis, wound, eye and burn infections [4]. It is frequently found as coisolates with other pathogens, such as
Enterococcus species, Candida spp. in the samples of patients with biofilm related infections [5]. It was shown that expression of the virulence factors increased and resulted in greater tissue damage in parallel with the presence of polyspecies pathogens in the biofilm environment $[5,6]$.

Enterococcus species are gram positive bacteria and the harmless members of gut flora in humans and animals. They are among the most frequent causes of nosocomial infections since they have the ability to create colony in different human body sites as well as on the surface of medical devices and may exhibit resistance to many antibiotics [7]. It is now well known that these infections are mainly associated with biofilm formation and are difficult to treat [8].

Interspecies interactions in biofilms have been extensively studied in human body and environments [9-11]. Different microbial interactions could effect the biofilm composition. A study reported that the biofilm cell counts of Escherichia coli decreased when co-cultured with Pseudomonas aeruginosa, but P.aeruginosa obtained some advantages when grown in

How to cite this article: Kart D. The susceptibility of Proteus mirabilis and Enterococcus faecalis to various antimicrobial agents in polymicrobial biofilms formed using a drip flow reactor. Marmara Med J 2019; 32: 137-143. doi: 10.5472/marumj.637153 
dual-species biofilms [12]. However, there is little information about antimicrobial susceptibility profile (such as antibiotics, disinfectants etc.) of polymicrobial biofilms. The results of a study showed that a multispecies biofilm with six different bacterial species including Acinetobacter calcoaceticus had the highest resistance to sodium hypochlorite $(\mathrm{NaOCl})$, while a multispecies biofilm without A.calcoaceticus was more susceptible to $\mathrm{NaOCl}$ compared to the monospecies biofilms. No significant difference was reported in a previously published study in susceptibility to ethanol between mono - and multispecies biofilms of Candida albicans and Staphylococcus aureus [13]. Kart et al. concluded that the effect of the disinfectants tested in a multispecies biofilm depends on the type of the strain and the kind of the disinfectant used [14].

Dynamic mono and dual species biofilm models of E. faecalis and P.mirabilis which were reported as frequently isolated species from catheter-associated polymicrobial infections were developed in this study in a repeatable style using Drip Flow Biofilm Reactor (DFR) [15].

The aim of this study is to evaluate the effect of dual species interactions between E.faecalis and P.mirabilis in the developed biofilm models on individual susceptibility against various antimicrobial agents such as antibiotics (ampicillin and ciprofloxacin), disinfectants (Quarternery Ammonium Compound (QAC), hydrogen peroxide, glutaraldehyde) and probiotic strains.

\section{MATERIALS and METODS}

\section{Bacterial strains}

P. mirabilis ATCC 29906, E. faecalis ATCC 47077/OG1RF, B. lactis ATCC 27536 and L. acidophilus ATCC 4356 were used in the study. P.mirabilis ATCC 29906 and E.faecalis ATCC $47077 /$ OG1RF were grown overnight at $37^{\circ} \mathrm{C}$ in brain heart infusion (BHI) broth (Oxoid, Basingstoke, UK).

B.lactis ATCC 27536 and L.acidophilus ATCC 4356 were cultured in Man-Rogosa-Sharpe broth (MRSB; Merck, Darmstadt, Germany) and incubated at $37^{\circ} \mathrm{C}$ in an anaerobic jar for $18 \mathrm{~h}$ and maintained on MRS agar plates (MRSA; Merck, Darmstadt, Germany).

\section{Preparation of cell-free culture supernatant of probiotic strains}

After incubating L. acidophilus and B.lactis strains in MRS broth at $37{ }^{\circ} \mathrm{C}$ for $18 \mathrm{~h}$, the cultures were centrifugated at $8000 \mathrm{xg}$ for $20 \mathrm{~min}$ at $4{ }^{\circ} \mathrm{C}$ to obtain the cell-free supernatants. Then, the supernatants were filtered through $0.2-\mu \mathrm{m}$ syringe filter (Millipore, Bedford, MA, USA) [9].

\section{Antimicrobial agents}

Disinfectants, antibiotics and probiotic strains tested in the study were shown in Table I. All disinfectant solutions were prepared using water of standard hardness (WSH), filtersterilized and stored at $4^{\circ} \mathrm{C}$ for up to 1 month. Sterile WSH distilled water and MRS broth were used as positive controls for antimicrobial activities of the disinfectants, antibiotics and probiotic supernatants, respectively.

Table I. Antimicrobials used in the study

\begin{tabular}{|c|c|c|}
\hline $\begin{array}{l}\text { Disinfectants/ } \\
\text { Other antimicrobials }\end{array}$ & $\begin{array}{l}\text { Concentration } \\
(\% / \mathrm{mg} / \mathrm{ml})\end{array}$ & $\begin{array}{l}\text { Contact Times } \\
\text { (minutes/ } \\
\text { hours) }\end{array}$ \\
\hline Quarternery Ammonium Compound (QAC) & $3 \%$ & $15 \mathrm{~min}$. \\
\hline Quarternery Ammonium Compound (QAC) & $1.5 \%$ & $15 \mathrm{~min}$. \\
\hline Hydrogen peroxide $\left(\mathrm{H}_{2} \mathrm{O}_{2}\right)$ & $1.5 \%$ & $5 \mathrm{~min}$. \\
\hline Hydrogen peroxide $\left(\mathrm{H}_{2} \mathrm{O}_{2}\right)$ & $0.75 \%$ & $5 \mathrm{~min}$. \\
\hline Gluteraldehyde & $2 \%$ & $15 \mathrm{~min}$. \\
\hline Gluteraldehyde & $1 \%$ & $15 \mathrm{~min}$. \\
\hline Ampicillin & $32-1024 \mu \mathrm{g} / \mathrm{ml}$ & $24 \mathrm{~h}$. \\
\hline Ciprofloxacin & $32-1024 \mu \mathrm{g} / \mathrm{ml}$ & $24 \mathrm{~h}$. \\
\hline $\begin{array}{l}\text { Probiotic supernatants } \\
\text { (B. lactis ATCC } 27536 \text { and L. acidophilus } \\
\text { ATCC4356) }\end{array}$ & - & $24 \mathrm{~h}$. \\
\hline
\end{tabular}

\section{Development of mono - and dual-species biofilms in}

\section{Drip Flow Reactor Model}

Biofilms consisting of P.mirabilis and E.faecalis were grown in DFR (Bio Surface Technologies Corp, Montana, USA) with low shear and continous flow approved by the American Society for Testing and Materials International (ASTM) standard setting organization [15]. Final inoculum suspensions $\left(10^{6} \mathrm{CFU} / \mathrm{ml}\right)$ of both bacteria were prepared in $10 \mathrm{ml} \mathrm{BHI}$ broth and placed into the DFR, which comprises six individual, parallel test channels including sterile slide (Figure 1). After operating the reactor in batch mode for $6 \mathrm{~h}$, the flow was started and maintained for another $48 \mathrm{~h}$ with a continuous flow rate of $0.82 \mathrm{ml} / \mathrm{min}$ per channel [16]. During continuous flow, the media was dripped onto the surface of slides set at a $10^{\circ}$ angle and mature biofilms were formed on these slides. The microorganisms were cultured alone (for mono species biofilms) and together (for dual-species biofilms).

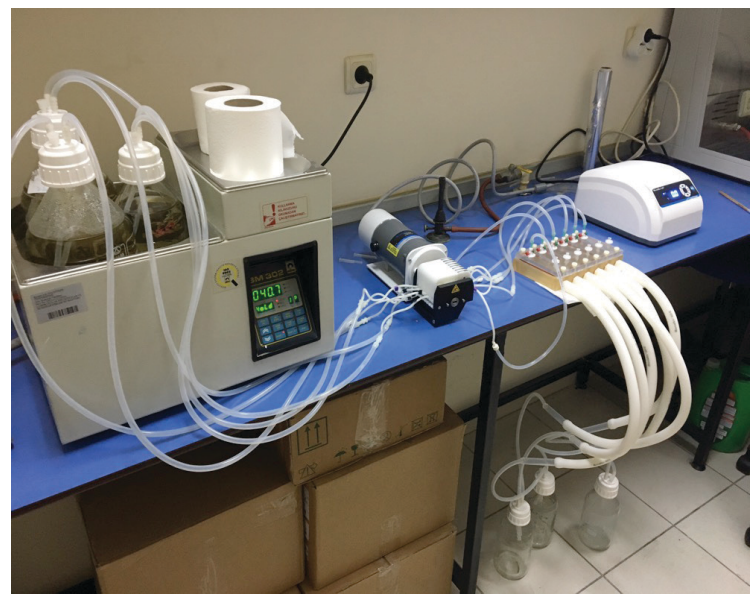

Figure 1. Drip flow reactor used in the study 


\section{Anti-biofilm evaluation}

The prescribed concentrations and contact times of each agents were applied to the slides which mono and dual-species biofilms of the strains were formed on (Table I). After the contact time, the disinfectant was neutralized with Dey-Engley neutralizing broth, as described previously [13,14]. For the ampicillin and ciprofloxacin, all concentrations (ranging from 1024 to 32 $\mathrm{mg} / \mathrm{ml}$ ) were tested in each of the six channel, individually, at same time. The supernatants of B. lactis ATCC 27536 and L. acidophilus ATCC 4356 were obtained after centrifugating the overnight cultures of both strains in MRS broth (Merck, Darmstadt, Germany) and were transferred onto the pre-formed mature biofilms to evaluate their anti-biofilm effects.

\section{Colony counting}

After treatments, the slide samples were removed from the reactor channels and rinsed with sterile buffered saline solution to remove planktonic cells. Biofilms were scraped from the slide surfaces with the cell scrapper and clumps were disaggregated by vortexing and sonication steps (at a frequency of $42 \mathrm{kHz}$ (model 2510 sonicating water bath; Branson, New Hampshire,USA) according to the published protocols [17]. After dissagregating, the biofilm suspensions were serially diluted in sterile buffered saline solution and plated triplicate on selective growth media; ie tryptic soy agar (containing 1.5\% agar) supplemented with vancomycin $(16 \mu \mathrm{g} / \mathrm{ml})$ for P.mirabilis and bile esculin azid agar for E.faecalis, respectively. Following $24 \mathrm{~h}$ of incubation time, the colonies were counted as colony forming units per milliliter $(\mathrm{cfu} / \mathrm{ml})$.

\section{Scanning electron microscopy (SEM)}

After the mature biofilm formations, the slides were removed from DFR, rinsed with $1 \mathrm{ml}$ of buffered saline solution and cutted with glass diamond. Subsequently, all parts were washed with sterile distilled water and fixed in a buffer containing $2 \%$ glutaraldehyde and $0.1 \mathrm{M}$ cacodylate for $30 \mathrm{~min}$ followed by rinsing three times for 10 minutes in $0.2 \mathrm{M}$ cacodylate buffer. After passing them through serial ethanol solutions, samples were dried, then coated with gold-palladium and examined by a scanning electron microscope [18].

\section{Statistical analysis}

The colony counts were recorded for each treatment as $\log 10$. All statistical calculations were performed on the log density values. Statistical analysis was performed using two-tailed t-test assuming unequal variances with $\alpha=0.5$ and a $\mathrm{p}$ value $<0.05$ was considered to be significant.

\section{RESULTS}

Single and dual-species inoculum suspensions containing $10^{6} \mathrm{cfu} /$ $\mathrm{ml}$ of E. faecalis and P. mirabilis in BHI was added to each channel of the DFR to form mature biofilms. In single and dual-species biofilms E. faecalis and P. mirabilis were grown up to $\sim 10^{7} \mathbf{c f u} / \mathbf{m l}$ and $\sim 10^{8} \mathrm{cfu} / \mathrm{ml}$ respectively. Compared to single species biofilm, the results demonstrated that the survival rate of each species was not affected with the other one. The cell numbers in the biofilm following treatment with the disinfectants were determined by plating onto the selective media concerning the results (Table II). All cells were death after treatment with two other disinfectants. Except $\mathrm{H}_{2} \mathrm{O}_{2}$, all other disinfectants led to cell death in all biofilm formations with either $P$. mirabilis or $E$. faecalis in single species and in dual-species biofilm (Table II).

Table II. Efficacy of disinfectants on biofilm

\begin{tabular}{|c|c|c|c|c|c|c|}
\hline \multicolumn{3}{|c|}{ Disinfectant } & \multicolumn{2}{|c|}{ P.mirabilis } & \multicolumn{2}{|c|}{ E.faecalis } \\
\hline & $\begin{array}{c}\text { Conc. } \\
(\%)\end{array}$ & $\begin{array}{l}\text { Time } \\
\text { (min.) }\end{array}$ & Mono & Dual & Mono & Dual \\
\hline $\mathrm{H}_{2} \mathrm{O}_{2}$ & 2 & 5 & $95.71 \pm 0.4$ & $99.93 \pm 0.01$ & $99.47 \pm 0.1+$ & $88.42 \pm 1.2$ \\
\hline $\mathrm{H}_{2} \mathrm{O}_{2}$ & 1 & 5 & $86.91 \pm 1.5=$ & $98.28 \pm 0.3$ & $93.12 \pm 0.7+$ & $73.26 \pm 1.7$ \\
\hline $\mathrm{QAC}^{*}$ & 3 & 15 & $99.99 \pm 0.0$ & $99.99 \pm 0.0$ & $99.99 \pm 0.0$ & $99.99 \pm 0.0$ \\
\hline QAC $^{*}$ & 1.5 & 15 & $99.99 \pm 0.0$ & $99.96 \pm 0.01$ & $99.99 \pm 0.0$ & $99.99 \pm 0.0$ \\
\hline $\mathrm{GA}^{*}$ & 2 & 15 & $100 \pm 0.0$ & $100 \pm 0.0$ & $100 \pm 0.0$ & $100 \pm 0.0$ \\
\hline $\mathrm{GA}^{*}$ & 1 & 15 & $100 \pm 0.0$ & $100 \pm 0.0$ & $100 \pm 0.0$ & $100 \pm 0.0$ \\
\hline
\end{tabular}

The results are expressed as hundred percent effective and are shown as the average \pm standard error $(n=3)$. ${ }^{*}$ Statistically significant reduction for all biofilm conditions compared to untreated control $(\mathrm{p}<0.05)$. +Significantly more cells of this organism are killed in a single-species biofilm than in a dual-species biofilm $(\mathrm{p}<0.05)$. =Significantly more cells of this organism are killed in the dual-species biofilm than in single-species biofilm ( $\mathrm{p}<0.05)$. $\mathrm{H} 2 \mathrm{O} 2$ : hydrogen peroxide, QAC: quarternery ammonium compounds, GA: Gluteraldehyde

The ampicillin and ciprofloxacin susceptibilities of $P$. mirabilis and $E$. faecalis cells both in single and dual species biofilms were determined individually. In comparison to untreated controls, none of the tested concentrations of ampicillin against $E$. facealis showed anti-biofilm activity both in single and dual-species biofilms (Figure 2). In contrast, a significant decrease in cell survival of $P$. mirabilis was determined only with $1024 \mu \mathrm{g} / \mathrm{ml}$ among all the tested concentrations of ampicillin both in single and dual species biofilms (Figure 2). Statistically significant difference was obtained between susceptibilities of single and dual species biofilms formed by $P$. mirabilis. Accordingly, in the presence of $E$. faecalis, the biofilm cells of P.mirabilis were found to be less susceptible to ampicillin $(1024 \mu \mathrm{g} / \mathrm{ml})$.

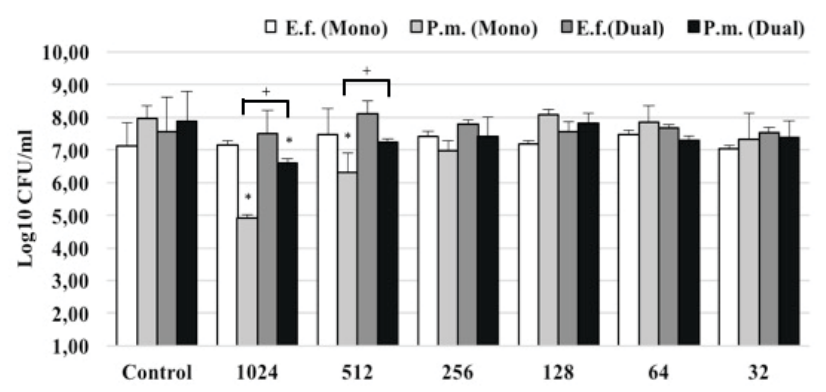

Figure 2. The effect of ampicillin on mono and dual species biofilms of E.faecalis and P.mirabilis

*Statistically more significant decrease in the cell counts than control $(\mathrm{p}<0.05)$ + Significantly more cells of this organism were killed in a monospecies biofilm than in a dual-species biofilm $(\mathrm{p}<0.05)$ 
The significant decrease in the growth of E. faecalis cells both at 512 and $1024 \mathrm{mg} / \mathrm{ml}$ concentrations of ciprofloxacin were obtained in single and also in dual-species biofilm when compared to the untreated control (Figure 3). It was concluded that the ciprofloxacin showed more inhibitory activity against P. mirabilis than E. faecalis as the significant decrease in cell growth in $P$. mirabilis single species biofilm was obtained even at the lowest tested concentration $(32 \mathrm{mg} / \mathrm{ml}$ ) (Figure 3 ). Furthermore, the cells in single species biofilm formed by P.mirabilis were more susceptible to both tested antibiotics when compared to dual species biofilm (Figure 3).

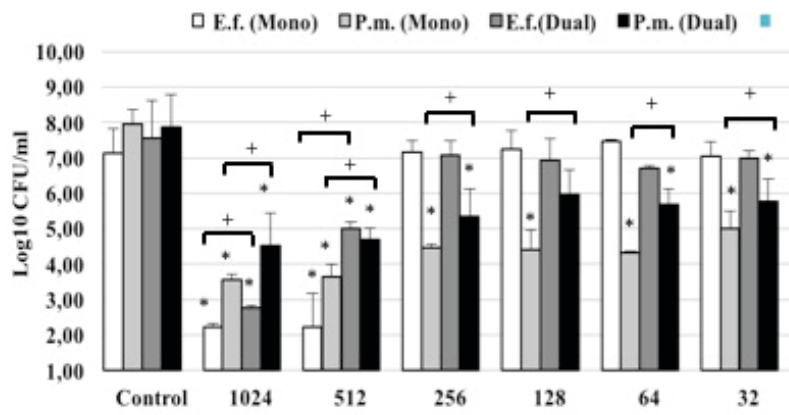

Figure 3. The effect of ciprofloxacin on mono and dual species biofilms of E.faecalis and P.mirabilis

${ }^{*}$ Statistically more significant decrease in the cell counts than control $(\mathrm{p}<0.05)$ + Significantly more cells of this organism were killed in a monospecies biofilm than in a dual-species biofilm $(\mathrm{p}<0.05)$

When the results of the effect of two probiotic supernatants on the cell survival were reviewed, $L$. acidophilus was found to be more effective both on single and dual species compared to $B$. lactis. None of the probiotic supernatants showed anti-biofilm effect on E. faecalis. cells in dual species biofilm. However the significant decrease in the cell growth of E. faecalis was obtained by $L$. acidophilus supernatant treatment in the single species biofilm (Figure 4). The dense cell populations of $P$. mirabilis and $E$. faecalis were observed in mono and also in dual-species biofilms by SEM images (Figure 5).

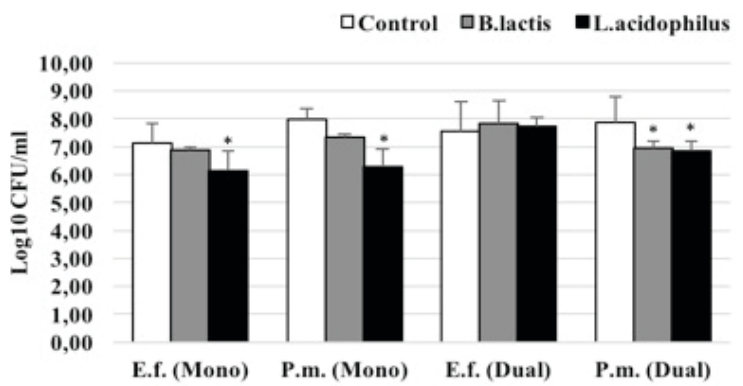

Figure 4. The antimicrobial effects of probiotic supernatants on the biofilms of E.faecalis and P.mirabilis.

*Statistically more significant decrease in the cell counts than control $(\mathrm{p}<0.05)$

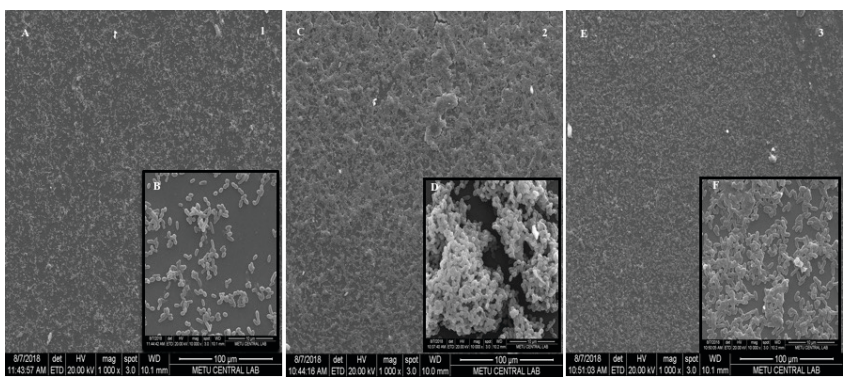

Figure 5. Scanning electron microscopy (SEM) images of biofilms

1. Dual-species biofilm of E. faecalis and P.mirabilis 2. E. faecalis 3. P. mirabilis (A,C,E): SEM images magnified by $1000 \mathrm{X}$. (B,D,F): SEM images magnified by $10000 \mathrm{X}$

\section{DISCUSSION}

The anti-biofilm susceptibilities of E. faecalis and P. mirabilis cells against three different disinfectant were determined both in single and dual species biofilms, individually. Except for $\mathrm{H}_{2} \mathrm{O}_{2}$, our results demonstrated that all tested concentrations of glutaraldehyde and QAC effectively kill more than $99.999 \%$ of cells both in mono and dual-species biofilms. In previously published reports it was reported that monospecies biofilms are often more susceptible to antimicrobial agents than polyspecies biofilms $[3,19]$. On contrary, our results clearly suggested that the efficacy of $\mathrm{H}_{2} \mathrm{O}_{2}$ was dependent on the type of microbial species present in the biofilm environment. Compared to its mono species biofilm $P$. mirabilis was found to be more susceptible to $\mathrm{H}_{2} \mathrm{O}_{2}$ when it was co-cultured with E. faecalis. On the other hand, E. faecalis was found to be less susceptible to $\mathrm{H}_{2} \mathrm{O}_{2}$ in the dual species biofilm with $P$. mirabilis compared to its mono species biofilm. These results support our previously published data indicating that the antimicrobial susceptibility of biofilm cells was dependent on both the nature of microbial species and properties of the selected disinfectant [14]. In our previous study, $\mathrm{H}_{2} \mathrm{O}_{2}$ was found to kill $96.94 \%$ of $P$. aeruginosa cells in a triple-species biofilm consisting of $P$. aeruginosa, $S$. aureus and $C$. albicans, whereas $P$. aeruginosa cells in a singlespecies biofilm were not affected [14]. Alfa et al. evaluated the ability of different high-level disinfectants, frequently used for endoscope reprocessing to remove the single-species biofilms of E. faecalis and P. aeruginosa, separately. They have concluded that high-level disinfectants such as glutaraldehyde and $\mathrm{H}_{2} \mathrm{O}_{2}$ were insufficient to completely kill the biofilm cells when the high numbers of cells were found in the environment [20].

The results of glutaraldehyde activity obtained from the presented study were not consistent with the literature. This difference may be caused by using different protocols (flow based system versus static conditions) in the studies. In a study reported by Bock et al, the efficacy of $\mathrm{H}_{2} \mathrm{O}_{2}$ based disinfectants was investigated against biofilms formed by multi-drug resistant Acinetobacter spp., Klebsiella pneumoniae and P. aeruginosa. In comparison to planktonic forms the efficacies of recent working concentrations of disinfectants were not found to be susceptible 
[21]. Majority of the previously reported studies on biocide susceptibility of planktonic or single-species biofilm cells have not taken into consideration the effect of the co-existence of bacteria in a mixed biofilm on individual biocide susceptibility. In the literature the reduced susceptibility to antibiotics in biofilm related infections formed by E. faecalis was attributed to biofilm-specific antimicrobial tolerance mechanisms [22]. Penetration limitation is one of these mechanisms and basically defined as the limited diffusion of the antibiotics into the biofilm matrix thus only the surface of the biofilm can get into contact with the antibiotic $[23,24]$.

The MIC values of the antibiotics commonly used in treatment of the planktonic form of pathogen microorganisms are insufficient to eradicate the biofilm-embedded counterparts [25]. Due to the lack of standards and specific breakpoints for anti-biofilm assays biofilm susceptibility tests are not currently used in clinical diagnostic routines [26]. In this study ampicillin was found to be insufficient to eradicate the E. faecalis biofilm cells both in mono and dual-biofilms. For high concentrations of ciprofloxacin $(1024$ and $512 \mu \mathrm{g} / \mathrm{ml})$, the log reduction in viable population was determined as approximately 4.5 and 3.5 in mono and dual-species biofilms respectively. These results were found to be in accordance with the results of two recently published studies [26].

In the present study the influence of coexistence of $P$. mirabilis with E. faecalis in dual-species biofilm on the susceptibility of P. mirabilis against ciprofloxacin and ampicillin was evaluated. Compared to its single-species biofilm, $P$. mirabilis showed less susceptibility to both antibiotics in dual-species biofilm (Figure 2 and 3). The interaction of two bacteria was resulted with the decrease of P.mirabilis susceptibility to the tested antibiotics with an unknown mechanism. Ampicillin significantly decreased the number of $P$. mirabilis viable cells in mono and also in dualspecies biofilms at 1024 and $512 \mathrm{mg} / \mathrm{ml}$ concentrations (Figure 2 ). Statistically significant decrease was determined in mono and dual-biofilm cells of P.mirabilis at $32 \mu \mathrm{g} / \mathrm{ml}$ concentration of ciprofloxacin.

In a previously published study concerning dual species biofilm formed by P.aeruginosa and P. mirabilis, the inhibitory activity of P. mirabilis on $P$. aeruginosa has been reported. By the authors this inhibition was attributed to less biofilm biomass of $P$. aeruginosa in dual species biofilm than the single species biofilm [27]. The susceptibilities of P.mirabilis biofilm cells against eight different antimicrobial agents including amoxicillin, erythromycin, gentamicin, nitrofurantoin, ciprofloxacin, trimethoprimesulfamethoxazole, ceftriaxone and chloramphenicol were tested by Wasfi et al. Among these agents ciprofloxacin and ceftriaxone both at $8 \mu \mathrm{g} / \mathrm{ml}$ concentration were found to be the most effective agents which removed up the pre-formed biofilms by $34-55 \%$ and $33-69 \%$, respectively [28]. Another study determined the eradicating effect of ciprofloxacin against the biofilm forming isolates of $P$. mirabilis at four antibiotic concentrations, corresponding to $0.125 \mathrm{MIC}, 0.25 \mathrm{MIC}, 0.5 \mathrm{MIC}$ and 1 MIC values [29].

Previously, it was shown that lactobacilli could break down cells of opportunistic pathogenic bacteria [30]. However, there was limited information about the interactions between Lactobacillus and other bacteria that occurred during mixed-biofilm formation. Compared to B. lactis, L. acidophilus was found to be more effective on P.mirabilis cells both in single and dualspecies biofilms than E.faecalis. Based on our findings, it can be concluded that probiotics may display distinct antimicrobial effects on individual species of mixed-biofilms. Rybalchenko et al. concluded that a probiotic strain, L. fermentum 97, suppressed the growth of Staphylococcus spp., Enterobacteriaceae and C. albicans biofilm cells [30]. In another study, the growth inhibition of Streptococcus mutans by L. acidophilus LA-5 was observed significantly [31].

In conclusion, the cells in dual-species biofilm may display different responses to antimicrobialagents than their counterparts in single-species biofilm. This study investigated the effects of microbial interactions in dual-species biofilms of $P$. mirabilis and $E$. faecalis on their responses to various antimicrobial agents in a flow-based biofilm reactor model. Single or dual-species biofilm models were successfully developed by $P$. mirabilis and E. faecalis which were frequently co-isolated from the samples of patients with CAUTI. Findings of this study demonstrated that glutaraldehyde and quaternary ammonium compounds are the agents that might be effectively used to eradicate biofilms in the hospital cleaning settings. Ampicillin and ciprofloxacin are antibiotics used to treat the urinary system infections caused by urinary pathogens such as E. faecalis and P. mirabilis. In the study, concentrations lower than $512 \mu \mathrm{g} / \mathrm{ml}$ were found to be insufficient to kill $E$. faecalis biofilm cells in single and dualspecies biofilms for both antibiotics. However, ciprofloxacin was able to decrease the number of viable cells of $P$. mirabilis at 32 $\mu \mathrm{g} / \mathrm{ml}$ both in mono and dual-species biofilms significantly. The presence of E. faecalis in the dual-species biofilm decreased the susceptibility of $P$. mirabilis to ciprofloxacin. Although, further studies are required, this study emphasized the importance of the microbial interactions in polymicrobial biofilms, especially in response to antimicrobials for the treatment of biofilmrelated diseases. Although, the effect of probiotic supernatants were found to be dependant on the nature of biofilm strain, $L$. acidophilus was more succesfull in killing bacterial cells when grown alone.

Conflict of Interest: The author declares that she has no conflict of interest.

Ethical Issues: According to the Institutional Ethical Committee this study did not require ethics approval as it was conducted on reference stains and the data did not contain patient-specific information.

\section{REFERENCES}

[1] Donlan RM, Costerton JW. Biofilms: survival mechanisms of clinically relevant microorganisms. Clin Microbiol Rev 2002;15:167-93. doi: 10.1128/Cmr.15.2.167.193.2002

[2] Peeters E, Nelis HJ, Coenye T. Evaluation of the efficacy of disinfection procedures against Burkholderia cenocepacia biofilms. J Hosp Infect 2008;70:361-8. doi: 10.1016/j. jhin.2008.08.015. 
[3] Harriott MM, Noverr MC. Candida albicans and Staphylococcus aureus form polymicrobial biofilms: effects on antimicrobial resistance. Antimicrob Agents Chemother 2009;53:3914-22. doi: 10.1128/Aac.00657-09.

[4] Armbruster CE, Mobley HLT. Merging mythology and morphology: the multifaceted lifestyle of Proteus mirabilis. Nat Rev Micro 2012;10:743-54. doi: 10.1038/nrmicro2890.

[5] Armbruster CE, Smith SN, Johnson AO, et al. The pathogenic potential of proteus mirabilis is enhanced by other uropathogens during polymicrobial urinary tract infection. Infect Immun 2017;85:e00808-16. doi:10.1128/IAI.00808-16.

[6] Armbruster CE, Forsyth-DeOrnellas V, Johnson AO, et al. Genome-wide transposon mutagenesis of Proteus mirabilis: Essential genes, fitness factors for catheter-associated urinary tract infection, and the impact of polymicrobial infection on fitness requirements. PLoS Pathog 2017;13: e1006434. doi: 10.1371/journal.ppat.1006434.

[7] Hidron AI, Edwards JR, Patel J, et al. NHSN annual update: antimicrobial-resistant pathogens associated with healthcareassociated infections: annual summary of data reported to the National Healthcare Safety Network at the Centers for Disease Control and Prevention, 2006-2007 Infect Control Hosp Epidemiol 2008;29:996-1011. doi: 10.1086/591861.

[8] Paganelli FL, Willems RJ and Leavis HL. Optimizing future treatment of enterococcal infections: attacking the biofilm? Trends Microbiol 2012;20:1. doi: 10.1016/j.tim.2011.11.001.

[9] Kolenbrander PE, Palmer RJ, Periasamy S, et al. Oral multispecies biofilm development and the key role of cellcell distance. Nat Rev Microbiol 2010;8:471-80. doi: 10.1038/ nrmicro2381.

[10] Burmolle M, Webb JS, Rao D, et al. Enhanced biofilm formation and increased resistance to antimicrobial agents and bacterial invasion are caused by synergistic interactions in multispecies biofilms. Appl Environ Microbiol 2016;72:391623. doi: 10.1128/Aem.03022-05.

[11] Schwering M, Song J, Louie M, et al. Multi-species biofilms defined from drinking water microorganisms provide increased protection against chlorine disinfection. Biofouling 2013;29:917-28. doi: 10.1080/08927.014.2013.816298.

[12] Galván EM, Mateyca C, Ielpi L. Role of interspecies interactions in dual-species biofilms developed in vitro by uropathogens isolated from polymicrobial urinary catheterassociated bacteriuria. Biofouling 2016;32:1067-77. doi: 10.1080/08927.014.2016.1231300.

[13] Peters BM, Ward RM, Rane HS, et al. Efficacy of ethanol against Candida albicans and Staphylococcus aureus polymicrobial biofilms. Antimicrob Agents Chemother 2013;57:74-82. doi: 10.1128/Aac.01599-12.

[14] Kart D, Tavernier S, Van Acker H, et al. Activity of disinfectants against multispecies biofilms formed by Staphylococcus aureus, Candida albicans and Pseudomonas aeruginosa. Biofouling 2014;30: 377-83. doi:10.1080/08927.014.2013.878 333.

[15] ASTM Standard E2647, 2008. Test method for quantification of Pseudomonas aeruginosa biofilm grown using drip flow biofilm reactor with low shear and continuous flow. ASTM International. doi:10.1520/e2647-13.

[16] Goeres D, Hamilton M, Beck N, et al. A method for growing a biofilm under low shear at the air-liquid interface using the drip flow biofilm reactor. Nat Protoc 2009;4:783-8. doi: 10.1038/nprot.2009.59.

[17] Goeres DM, Loetterle LR, Hamilton MA, et al. Statistical assessment of a laboratory method for growing biofilms. Microbiology 2005;151:757-62. doi: 10.1099/mic.0.27709-0.

[18] Wang L, Dong M, Zheng J, et al. Relationship of biofilm formation and gelE gene expression in Enterococcus faecalis recovered from root canals in patients requiring endodontic retreatment. J Endod 2011;37:631-6. doi:10.1016/j. joen.2011.02.006.

[19] Simoes LC, Simoes M, Vieira MJ. Influence of the diversity of bacterial isolates from drinking water on resistance of biofilms to disinfection. Appl Environ Microbiol 2010;76:6673-9. doi: 10.1128/Aem.00872-10.

[20] Luciano CC, Olson N, Tipple AFV, et al. Evaluation of the ability of different detergents and disinfectants to remove and kill organisms in traditional biofilm. Am J Infect Control 2016;44: e243-e249. doi: 10.1016/j.ajic.2016.03.040.

[21] Perumal PK, Wand ME, Sutton JM, et al. Evaluation of the effectiveness of hydrogen-peroxide-based disinfectants on biofilms formed by Gram-negative pathogens. J Hosp Infect. 2014;87: 227e233. doi: 10.1016/j.jhin.2014.05.004.

[22] Lewis K. Riddle of biofilm resistance. Antimicrob Agents Chemother 2001;45:999-1007. doi: 10.1128/Aac.45.4.9991007.2001.

[23] Anderl JN, Franklin MJ, Stewart PS. Role of antibiotic penetration limitation in Klebsiella pneumoniae biofilm resistance to ampicillin and ciprofloxacin. antimicrob Agents Chemother 2000;44:1818-24. doi: 10.1128/Aac.44.7.18181824.2000.

[24] Kumon H, Tomochika K, Matunaga T, et al. A sandwich cup method for the penetration assay of antimicrobial agents through Pseudomonas exopolysaccharides. Microbiol Immunol 1994;38:615-9.

[25] Jensen ET, Kharazmi A, Lam K et al. Human polymorphonuclear leukocyte response to Pseudomonas aeruginosa grown in biofilms. Infect Immun 1990;58:2383-5.

[26] Thieme L, Klinger-Strobel M, Hartung A, et al. In vitro synergism and anti-biofilm activity of ampicillin, gentamicin, ceftaroline and ceftriaxone against Enterococcus faecalis. J Antimicrob Chemother 2018;73:1553-61. doi: 10.1093/jac/ dky051.

[27] Li X, Lu N, Brady HR. Biomineralization strongly modulates the formation of Proteus mirabilis and Pseudomonas aeruginosa dual-species biofilms. FEMS Microbiol Ecol 2016;92:fiw189. doi: 10.1093/femsec/fiw189.

[28] Wasfi R, Abd El-Rahman OA, Mansour LE, et al. Antimicrobial activities against biofilm formed by Proteus mirabilis isolates from wound and urinary tract infections. Indian J Med Microbiol 2012;30:76-80. doi: 10.4103/0255-0857.93044. 
[29] KwieciNska-Pirog J, Skowron K, Zniszczol K, et al. The assessment of Proteus mirabilis susceptibility to ceftazidime and ciprofloxacin and the impact of these antibiotics at subinhibitory concentrations on Proteus mirabilis biofilms. BioMed Res Int 2013;2013; 930876. doi: 10.1155/2013/930876.

[30] Rybalchenko OV, Bondarenko VM, Orlova OG, et al. Inhibitory effects of Lactobacillus fermentum on microbial growth and biofilm formation, Arch Microbiol 2015;197:102732. doi: 10.1007/s00203.015.1140-1.

[31] Schwendicke F, Korte F, Drfer CE, et al. Inhibition of Streptococcus mutans Growth and Biofilm Formation by Probiotics in vitro. Caries Res 2017;51:87-95. doi: $10.1159 / 000452960$. 